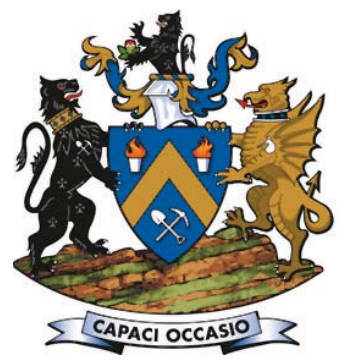

\title{
Mineral Resource and Mineral Reserve governance and reporting for AngloGold Ashanti
}

\author{
by R. Peattie, V. Chamberlain, and T. Flitton
}

\section{Synopsis}

Mineral Resource and Mineral Reserve governance is the comprehensive, overarching management process by which the Mineral Resource and Mineral Reserve is estimated, managed, and reported. Mineral Resource and Mineral Reserve governance provides the Board of Directors and investors with assurance on the integrity of the reported Mineral Resource and Mineral Reserve, which is the primary asset of the company and upon which investment decisions are based. The framework for Mineral Resource and Mineral Reserve governance of a company must be compliant with all regulatory codes as well as internal company policies and procedures. It is critical to ensure that reporting is transparent, appropriate, timeous, and reliable. Good Mineral Resource and Mineral Reserve governance should also ensure that all components in the estimation (from exploration to processing) of the Mineral Resource and Mineral Reserve are auditable and defendable. AngloGold Ashanti (AGA) is acutely aware that its primary asset is its Mineral Resource and Mineral Reserve, and has therefore established a formal Mineral Resource and Mineral Reserve governance process that has been structured to ensure that the Executive Committee and the Board have line of sight to the annual Mineral Resource and Mineral Reserve Public Reporting, as well as the review findings from a stringent internal and external review programme.

Keywords

SAMREC, governance, Mineral Resource, Mineral Reserve, Competent Person.
To simplify this process and provide standardization, AGA manages its Mineral Resource and Mineral Reserve reporting in terms of the SAMREC Code, supported by internal guidelines. The internal guidelines are set out to ensure the reporting of Exploration Results, Mineral Resources, and Mineral Reserves is consistently undertaken in a manner in accordance with AGA's business expectations and also in compliance with internationally accepted codes of practice adopted by AGA. The document outlines the minimum requirement for reporting to ensure that the process is consistent and transparent across AGA.

AGA follows a process-driven approach to the reporting of its Mineral Resource and Mineral Reserve. The lead is taken by the AGA Mineral Resource and Ore Reserve Reporting Committee (RRSC), whose membership and terms of references are mandated under a policy document signed off by the Chief Executive Officer. Its primary function is as a facilitator of the process, setting the requirements and the standards of quality.

AGA recognizes that the reporting of AGA's Mineral Resource and Mineral Reserve is the responsibility of the company acting through its Board of Directors; with access to the Board being through the Board Audit Committee. The final published outcome is based on Mineral Resource and Mineral Reserve reports and supporting documentation prepared by Competent Persons (CPs). To achieve this outcome and ensure regulatory approval, all CPs are members of SACNASP, ECSA, or SAGC, or are a Member or Fellow of the SAIMM, the GSSA, IMSSA, or a Recognized Professional Organization (RPO). ('the JORC Code') in 1989 and the subsequent publishing of the South African Code for the Reporting of Exploration Results, Mineral Resources and Mineral Reserves (the SAMREC Code) in 2007, AGA quickly recognized that the processes in place within the company for the reporting of Mineral Resources and Mineral Reserves were inadequate for the evolving regulatory environment. In response, the company embarked on a 10-year journey to develop a far more formalized, structured, and standardized approach to reporting.
* AngloGold Ashanti, South Africa.

(c) The Southern African Institute of Mining and Metallurgy, 2017. ISSN 2225-6253. This paper was first presented at the SAMREC/SAMVAL Companion Volume Conference 'An Industry Standard for Mining Professionals in South Africa', 17-18 May 2016, Emperors Palace, Johannesburg 


\section{Mineral Resource and Mineral Reserve governance and reporting for AngloGold Ashanti}

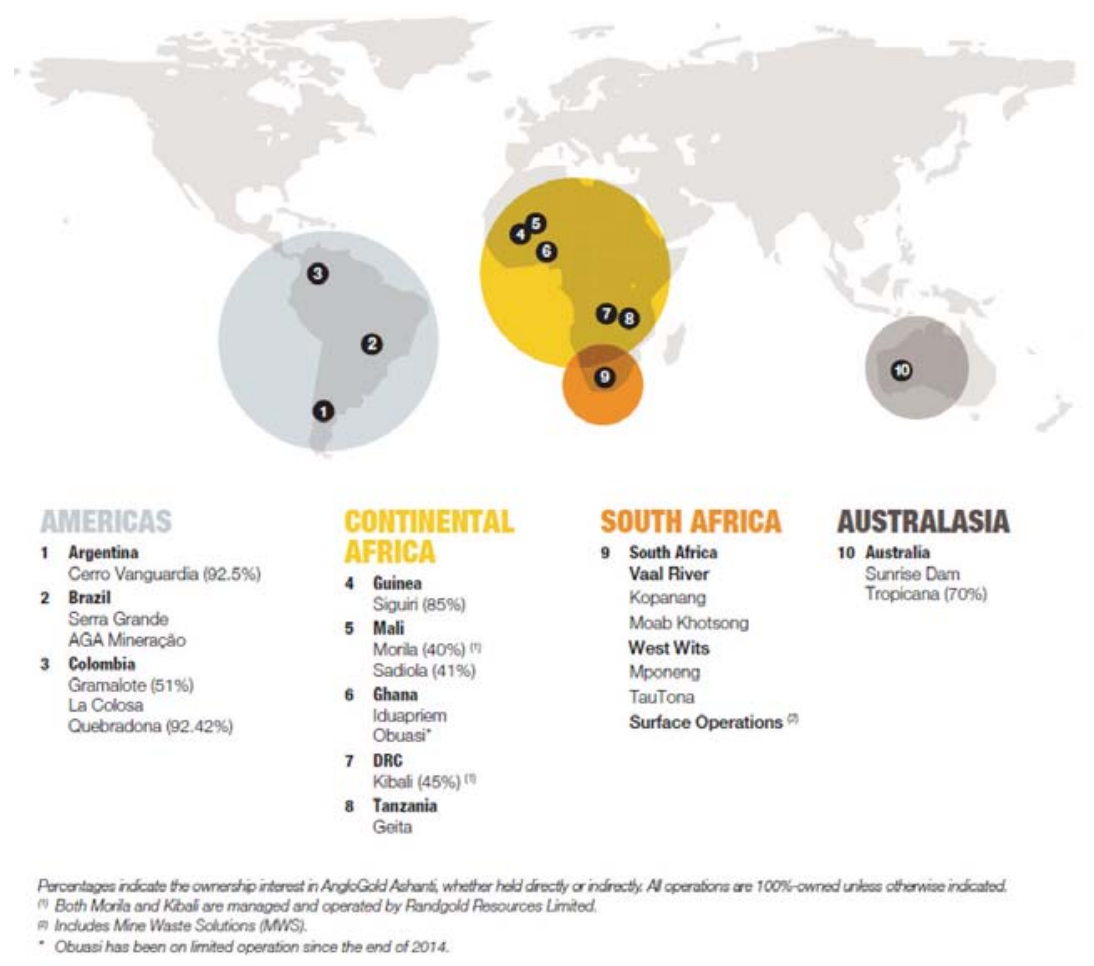

Figure 1-Locality of AGA operations and projects

The CPs also need to have a minimum of five years' relevant experience in the style of mineralization and type of deposit under consideration and in the activities they are undertaking.

Appointment of the individual CPs is by the General Manager, with oversight and ratification by the RRSC. Two CPs are appointed for each operation, one for Mineral Resources and the other for Mineral Reserves.

\section{AngloGold Ashanti process}

\section{Mineral Resource and Ore Reserve Steering Committee}

The RRSC, which meets at least once a quarter, comprises representatives from the relevant technical disciplines as well as regional representatives. The Senior Vice President: Strategic and Technical chairs the RRSC to ensure the requisite level of authority is assigned to the Committee. The RRSC is responsible for setting and overseeing the company's Mineral Resource and Mineral Reserve governance framework and for ensuring that it meets the company's goals and objectives while complying with all relevant regularity codes. Its primary function is corporate assurance and its terms of reference and composition are fixed through a policy document approved by the Chief Executive Officer. They include:

> Providing Group guidelines for the reporting of Mineral Resources and Mineral Reserves

> Compilation of the Group's annual Mineral Resource and Mineral Reserve statement

> Engagement with external regulatory bodies such as JORC, SAMREC, and the SEC to ensure that AngloGold Ashanti's interests are protected
> Providing assurance that all Mineral Resource or Mineral Reserve reporting complies with the relevant reporting codes as well as internal Group guidelines

$>$ The ratification of $\mathrm{CPS}$

> Ensuring regular external reviews of Mineral Resources and Mineral Reserves.

The key outputs of the RRSC are the annual Mineral Resource and Mineral Reserve report and the requisite internal Group guidelines for the reporting of Mineral Resources and Mineral Reserves.

Due to the ever-evolving regularity environment, a key aspect of the RRSC is to continuous align itself to the changes and ensure the timeous briefing and training of the CPS.

\section{Guidelines for the Reporting of the Mineral Resource and Mineral Reserves}

The Group guidelines for the reporting of the Mineral Resource and Mineral Reserve is an annual document that formalizes AGA's interpretation of the various listing requirements, regulatory frameworks, and reporting codes, including the Johannesburg Stock Exchange (JSE) and the Securities and Exchange Commission (SEC), SAMREC, and JORC, and provides the necessary company context and detail required for the estimation and reporting of Mineral Resources and Mineral Reserves on an annual basis. It is a live document that is reviewed on an annual basis and whose owner is the RRSC.

To ensure compliance with internationally accepted codes of practice adopted by AngloGold Ashanti, the main principles inherent in the language of the document are transparency, materiality, and competence.

To consistently achieve these principles across the 


\section{Mineral Resource and Mineral Reserve governance and reporting for AngloGold Ashanti}

company, the guidelines provides the standardization and necessary detail regarding the material assumptions used in the declaration of the Mineral Resource and Mineral Reserve, including:

> Gold price and other critical economic parameters such as exchange rates

> Minimum reporting requirements for a new Mineral Resource and Mineral Reserve

> Detailed definition and work flows for Mineral Resource classification

> Guidelines for reporting reconciliation, cut-off grades, modifying factors, Inferred Mineral Resource in the business plan, Mineral Resource and Mineral Reserve below infrastructure, Mineral Resource sensitivities

> Guidelines for Competent Persons Reports (CPRs).

\section{Competent Persons}

Competency and the competent person $(\mathrm{CP})$ are an integral part of all of the reporting codes. AGA has recognized the importance of selecting the appropriate individuals with the relevant experiences and expertise to become CPs at its operations and projects across the world, and therefore has a formalized approach to the appointment of its CPs. CPs are appointed by the relevant manager of the operation in question and the appointments are ratified by the RRSC. CPs are preferably employed by AGA and are selected based on relevant experience with the style of mineralization and type of deposit under consideration and with the activity that they are undertaking.

To ensure that the CPs consent to the inclusion of Mineral Resource and Mineral Reserve information in the annual report, they sign a letter of consent once they have reviewed the information in the form and context in which it appears.

A critical aspect of this approval is ensuring that the legal tenure of each operation and project has been verified to the satisfaction of the accountable $\mathrm{CP}$ and all Mineral Reserves have been confirmed to be covered by the required mining permits or there is a realistic expectation that these permits will be issued.

Due to the different experience and skills sets required for the estimation and evaluation of Mineral Resources and Mineral Reserves, AGA has separate appointments for Mineral Resources and for Mineral Reserves. This is reinforced by a professional development and support structure to ensure that the $\mathrm{CP}$ is fully briefed on the evolving external governance and has the necessary network and training to ensure best practice.

A key aspect of the management of the CPs is the training and succession planning required to ensure the skills and experiences remain in-house to allow the ongoing reporting of the Mineral Resources and Mineral Reserves.

\section{Audit and Review Process}

Over more than a decade, AGA has developed and implemented a rigorous system of internal and external reviews aimed at providing assurance in respect of Mineral Resource and Mineral Reserve estimates. External reviews are done on selected operations, in line with AGA's policy that each operation or project will be reviewed by an independent third party on average once every three years. The external reviews focus on the identification of fatal flaws, and through impartiality they provide an independence verification that the reporting is in terms of the requirements of the various codes.

Internal peer reviews are completed on an annual basis before all annual information is captured by the CPs. This review consists of an informal process that involves the relevant $\mathrm{CP}$ having to defend their work to their peers, and a formal process where the reviewer will attempt to replicate aspects of the work independently.

The peer review process is seen as an integral aspect of the audit and review process in ensuring consistency, in propagating best practice across the company, and for the personal development of the individuals involved.

In addition, all variation in excess of $10 \%$ (net of depletion) in the individual operation or project's Mineral Resource and/or Mineral Reserve statement) requires a formal review by the RRSC.

\section{$R^{3}$}

AGA makes use of a web-based group reporting database called Resource and Reserve Reporting System (R3) for the compilation and authorization of Mineral Resource and Mineral Reserve reporting. $R^{3}$ is a fully integrated system for the reporting and reconciliation of Mineral Resources and Mineral Reserves that supports various regulatory reporting requirements, including the SEC and the JSE under SAMREC. AGA uses R3 to ensure that a documented chain of responsibility exists from the $\mathrm{CPs}$ at the operations to the company's RRSC.

The web-based reporting system provides a platform that ensures a single version of the truth is captured in a secure, auditable database that is workflow-enabled. The system has a comprehensive set of validation rules that include, but are not limited to, the following:

> The Mineral Resource needs to be captured/imported before the Mineral Reserve can be captured

- Mineral Reserve content cannot be greater than Mineral Resource content per project area

> Inclusive Mineral Resource content must always be greater than or equal to exclusive Mineral Resource context

$>$ The previous year and all changes in the reconciliation capture must sum up to the current year total for tons and grams

> The Inferred Mineral Resource in a business plan content cannot be greater than the inclusive Inferred Mineral Resource content.

This system is compliant with the guiding principles of the Sarbanes-Oxley Act of 2002 (SOX) and forms the supporting database from which the Mineral Resource and Mineral Reserve report is published on an annual basis. To support the reporting process, the system also contains a database of the various technical specialists and CPs, together with a record of their experience and qualifications. A clear division of responsibilities is assigned within the system that 


\section{Mineral Resource and Mineral Reserve governance and reporting for AngloGold Ashanti}

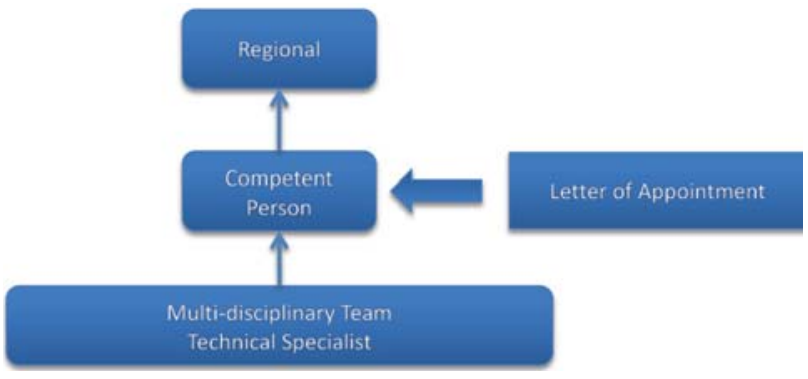

Figure 2-Chain of responsibility

requires a rigid hierarchy of work flow sign-offs; this ensures that the relevant people have access to the information for review and approval before it is made publicly available (Figure 2).

R3 assigns individual responsibilities that can be tracked and managed and allows remote access for data upload by the relevant technical specialists and approvals and consent by the CPs. Access, authorizations and work flow sign-off is through a unique secure login that allows a full audit trail.

R3, first conceptualized in 2003 and rolled out in 2004 as a data capture and company database of the Mineral Resource and Mineral Reserves, immediately proved itself by providing a single source of the truth and minimizing human error involved in handling large data-sets. Since then it has evolved into a fully integrated system for the reporting and reconciliation of Mineral Resources and Mineral Reserves that supports reporting to the SEC and the JSE under SAMREC. It achieves this by providing the relevant details, summaries, and reconciliations for end-of-year reporting, together with the necessary consents.

For any particular year of consideration, $\mathrm{R}^{3}$ provides the following information:

> Mineral Resource (inclusive and exclusive of Mineral Reserve) and the Mineral Reserve statement

> Inferred Mineral Resource used in business plan

> Mineral Resource and Mineral Reserve below infrastructure

> By-product information

> Reconciliations details

> Mineral Reserve modifying factors

> Professional details of all CPS

> Letters of appointment

> Letters of consent for publication

> Tenement information

$>$ CP Reports (CPRs)

$>$ Statement of competence

> Documented chain of responsibility

> JORC Table 1 and the SAMREC Table 1.

\section{Conclusion}

The foundation of AngloGold Ashanti's Mineral Resource and Mineral Reserve governance and reporting process is to ensure that the right people are doing the right work and that the information that is being made publicly available is fully vetted, compliant, and transparent, and therefore meets the guidelines in the South African Code for the Reporting of Exploration Results, Mineral Resources and Mineral Reserves (SAMREC Code).

To achieve this end, AGA has developed a rigorous Mineral Resource and Mineral Reserve governance and reporting process that is supported by a set of internal Group guidelines, a structure for the management of the process, and an integrated Group reporting database.

This is complemented by a combination of internal and external audits and reviews to ensure independence and impartiality and that the individual operations and projects are estimating and compiling their Mineral Resources and Mineral Reserves in accordance with the company guidelines and external regulatory requirements.

The sum result is a process that ensures that the Executive Committee of AGA and the Board through the Board Audit Committee have line of sight to the annual Mineral Resource and Mineral Reserve public reporting as well as the review findings from a stringent internal and external review programme, and thus the assurance in the integrity of the reported Mineral Resource and Mineral Reserve, which is the primary asset of the company and upon which investment decisions are based.

AGA recognizes that both the regulatory framework and the definition of best practice are continuously evolving, and that therefore it is important that the governance framework is sufficiently dynamic to respond to the ever-changing environment. Through the RRSC, AGA has the structure to both manage the Mineral Resource and Mineral Reserve governance and reporting process and react to these changes in a timely manner. The current process is a work in progress, and while it currently meets the corporate and governance requirement it is continuously being improved to keep pace with the regulatory changes and increases in corporate expectations.

\section{References}

AngloGold Ashantr. 2014. Mineral Resource and Ore Reserve Report. 192 pp.

AngloGold Ashanti. 2015. Guidelines for the reporting of Mineral Resources and Ore Reserve. Internal report. $57 \mathrm{pp}$

Canadian Securities Commissions (CSA). 2005. National Instrument 43-101. Standards for disclosure for mineral projects.

JORC. 2012. Australasian Joint Ore Reserves Committee. Australasian Code for Reporting of Exploration Results, Mineral Resources and Ore Reserves. The Joint Ore Reserves Committee of the Australasian Institute of Mining and Metallurgy, Australian Institute of Geoscientists, and Minerals Council of Australia. http://www.jorc.org/docs/JORC_code_2012.pdf

SAMREC. 2009. South African Mineral Resource Committee. The South African Code for Reporting of Exploration Results, Mineral Resources and Mineral Reserves (the SAMREC Code). 2007 Edition as amended July 2009. http://www.samcode.co.za/downloads/SAMREC2009.pdf

SAMREC. (2016). South African Mineral Resource Committee. The South African Code for the Reporting of Exploration Results, Mineral Resources and Mineral Reserves (the SAMREC Code). 2016 Edition. http://www.samcode.co.za/codes/category/8-reportingcodes?download=120:samrec 